\title{
COOPERACIÓN Y VOLUNTARIADO: Una aproximación a la figura del voluntariado en la Cooperación Internacional
}

\author{
Judit ORTEGA-AGUAZA; Juana María MORCILLO MARTÍNEZ \\ Observatorio de Cooperación al Desarrollo de la Universidad de Jaén (OBCUJA) \\ joaguaza@ujaen.es,morcillomartinezjuanamari@gmail.com
}

COOPERATION AND VOLUNTEERING: An approach to the figure of the volunteer in International Cooperation

Resumen: Este artículo de revisión analiza como las ONGs se definen como instituciones intermedias entre las instituciones gubernamentales y los individuos, que se constituyen voluntariamente para satisfacer necesidades sociales y culturales mediante aportaciones de esfuerzos humanos. Así mismo, entendemos el voluntariado como una actitud humana que busca construir una sociedad donde no predomine ningún tipo de marginación y/o exclusión social. En este sentido, en el marco de la Cooperación Internacional al Desarrollo conviven profesionales y voluntarios, que tienen que andar un mismo camino con funciones diferentes y que muchas veces se entremezclan. Por lo tanto, es importante tener en cuenta la necesidad de coordinar y organizar los recursos de forma optimizada con la finalidad de responder eficazmente a las necesidades de la población donde van dirigidas las actuaciones, buscando una dimensión cívica y política, dado que ambos aspectos, están estrechamente relacionados con la transformación social.

Abstract: This review article examines how NGOs are defined as intermediary institutions between government institutions and individuals, voluntarily associated to satisfy social and cultural needs by means of human efforts. Furthermore, we understand volunteering as a human attitude that seeks to build a society that is free from all forms of marginalization and/or social exclusion. In this regard, in the framework of International Development Cooperation are involved both professionals and volunteers, each one will have their own duties to perform but in places they are tangential to one another. Consequently, it is important to take into account the need to coordinate and manage the resources in an optimized way in order to respond efficiently to the needs of the population where the actions are aimed, seeking a civic and political dimension, as both aspects are closely linked to social transformation.

Palabras clave: 


\section{Introducción}

En las siguientes líneas nos centraremos a dilucidar algunos términos que serán utilizados de manera usual en este artículo de revisión, tales como: "cooperación", "solidaridad" y "desarrollo". A este tenor y siguiendo a Ruíz (2007): "cooperar" se entiende que tiene un sentido bidireccional, se da una relación de igual a igual mientras que "ayudar" supone socorrer es decir, de uno hacia otro sin que el otro dé nada.

Aun más revelador es el significado de solidaridad: "adhesión circunstancial a la causa o a la empresa de otros". Por lo tanto, establece el sentido contingente de la unión a los otros y deja bien claro que es la empresa del otro; de ese otro con el que se coopera o al que se ayuda. Procede de "sólido" que significa firme, macizo, denso y firme; asentado, establecido con razones fundamentales y verdaderas. Lo cual nos muestra la desviación que ha tenido el término puesto que mientras la solidaridad hoy en día se asocia a algo contingente, el adjetivo del que procede "sólido" indica todo lo contrario.

También ha evolucionado lo que se entiende por "desarrollo". Las distintas visiones de lo que es y significa el desarrollo de los pueblos o los países se puede observar estudiando las clásicas teorías sobre el mismo; desde la visión economicista basada en la equiparación de desarrollo a crecimiento económico; doctrinas de la modernización, teorías del crecimiento económico construidas sobre una línea espacio-temporal, a la visión estructuralista y dentro de ellas, las teorías de la dependencia (Rostov Ayuso, 2000).

Por otro lado, y haciendo alusión al término "voluntariado", lo definimos como una actitud que busca construir una sociedad más humana, solidaria e incluyente, teniendo como finalidad última contribuir a crear una sociedad sin exclusión o marginación, en la que las personas sean respetadas como seres humanos y sean partícipes, en condiciones de igualdad, en la solución de los problemas y en la creación de alternativas para una convivencia pacífica, siendo un instrumento fundamental para el desarrollo de la ciudadanía, en la consideración de que únicamente, de este modo, se puede conseguir una democracia plena y participativa.

Así mismo, podemos definir cinco tipos de voluntariado por grandes áreas de acción, que quedarían resumidos en los siguientes:

1. Acción social: es aquel en el que se colabora en un proyecto en el país donde se reside y en campos como la discapacidad, la migración, la exclusión, etc.

2. Voluntariado ambiental: es aquel relacionado con proyectos en defensa y protección del medio ambiente y animales.

3. Voluntariado en emergencias: es aquel relacionado con crisis y desastres puntuales, como pueden ser catástrofes naturales que afectan a poblaciones o vertidos.

4. Voluntariado en cooperación: es aquel relacionado con proyectos que se desarrollan en una comunidad perteneciente a un país distinto al que se reside. Hay organizaciones que prefieren denominar a este tipo de colaboración "turismo solidario" o "viaje solidario".

5. Voluntariado cultural: es aquel en el que se colabora en la organización de actividades en salas de arte, museos, bibliotecas y otros espacios o entidades relacionados con la cultura. Dentro de éste, es interesante el caso del voluntariado lingüístico en el que se promociona la colaboración en la enseñanza y promoción de uso de una lengua.

Del mismo modo, consideramos que voluntariado y cooperación son dos temas relacionados, no siendo totalmente interdependientes. De hecho, son dos espacios autónomos que tienen una parte en común, como es la cuestión del voluntariado en el ámbito de la 
cooperación internacional. Aunque, nuestra pretensión en este artículo es trabajar ambos conceptos por separado, ya que el contexto actual del marco de la cooperación internacional al desarrollo se caracteriza por una labor profesional tecnificada, con menos espacio para el voluntariado. Entendemos que ésta profesionalización es necesaria, pero desde esta perspectiva opinamos que el voluntariado, además de otorgarle a la experiencia de cooperación un cariz más humanitario, de encuentro entre culturas, o como una acción de transmisión de conocimientos, también aporta vivencias en la construcción de un nuevo modelo de desarrollo. Este sería un elemento consustancial al desarrollo humano por el que apostamos.

Precisamente, la cooperación para el desarrollo y la solidaridad internacional suponen un compromiso y una tarea de toda la sociedad. De hecho, el Estado español, se incorporó tarde al ámbito de la cooperación para el desarrollo (alrededor de los inicios de los ochenta) y aunque lentamente, a principios del siglo XXI, consiguió tener una política de cooperación seria, planificada, con recursos humanos y económicos similares a los países de nuestro entorno. Sin embargo, la crisis económica que vive España desde 2008 ha supuesto que todo el camino andado, especialmente durante la primera legislatura del gobierno Zapatero (2004-2008), se quede en poco, al retroceder nuestra política de cooperación a datos de los años ochenta. Y, es importante tener en cuenta que sigue siendo necesaria, siempre más que nunca, la toma de conciencia sobre los problemas que afectan a las condiciones de vida de buena parte de la humanidad.

En este sentido, en el primer apartado denominado: Voluntariado Social: un hecho significativo para el asociacionismo y, en una primera aproximación al tema, hacemos un breve repaso histórico, mostrando que el desarrollo del voluntariado en España posee algunas características diferenciales con respecto a los países más cercanos a nuestro entorno. Y, su evolución, ha quedado caracterizada por distintas etapas desde los años cuarenta hasta la actualidad. Del mismo modo, tratamos algunos conceptos básicos tales como Voluntariado en ONGs y ONG de desarrollo (ONGD).

En el segundo apartado denominado: La estructura de la Cooperación Internacional para el Desarrollo, señalamos los hitos más destacados de la cooperación para el desarrollo implementada en nuestro país, desde sus inicios, a principios de los años 80 .

Concluimos exponiendo que en el marco de la cooperación internacional al desarrollo conviven profesionales y voluntarios, que tienen que andar un mismo camino con funciones diferentes y que muchas veces se entremezclan. Este es un debate que se plantea en la acción social y que es necesario abordar. Quizás la contribución más importante del voluntariado a nuestra sociedad pasa por la creación de capital social, lo que genera efectos positivos en la eficacia de las instituciones democráticas, coadyuvando a la solución de los problemas colectivos y en el desarrollo económico. El voluntariado dota a la sociedad de una capacidad de gestión y de influencia en el que crece la democracia política, extendiendo esta democracia a otras parcelas diferentes de las del poder.

\section{Voluntariado social: un hecho significativo para el asociacionismo}

Al centrarnos en el término voluntariado social como un hecho significativo para el asociacionismo es importante tener en cuenta el concepto de solidaridad. Por ejemplo, ( $\mathrm{Zu}-$ bero, 2003, p. 16 ) al definir solidaridad pone el énfasis en: "las acciones de voluntariado, los valores morales y el capital afectivo que mueven a estas acciones caracterizadas como acciones individuales, que no tienen la denuncia como elemento idiosincrásico esencial", afirma que "en más de un aspecto, decir voluntariado y decir solidaridad es sustancialmente lo mismo, hasta el punto de que en muchas ocasiones, tanto entre los analistas del fenómeno voluntario como entre los participantes del movimiento, se habla indistintamente de organizaciones voluntarias o de organizaciones de solidaridad".

El voluntariado organizado es, básicamente, un movimiento cuyo objetivo fundamental 
es promover y sostener iniciativas ciudadanas de solidaridad. Si algo es -debe ser- el movimiento voluntario es una compleja y precisa máquina multiplicadora de solidaridad: el combustible del que se nutre es la solidaridad existente en el cuerpo social, solidaridad que devuelve a la sociedad purificada.

Así, cuando se hace alusión en un sentido amplio al término voluntariado, entendemos que sería aquella acción voluntaria que se desarrolla dentro de una organización sin ánimo de lucro por personas físicas que, de manera altruista y solidaria, intervienen con las personas y la realidad social, frente a situaciones de vulneración, privación o falta de derechos u oportunidades para alcanzar una mejor calidad de vida y una mayor cohesión y justicia social como expresión de ciudadanía activa organizada. (García-Rincón de Castro, 2003).

Del mismo modo, y de acuerdo con (Tavazza, 1995, p.4) el voluntariado es definido como la acción de "un ciudadano que, una vez cumplidos sus deberes de estado (estudios, familia, profesión) y civiles (vida administrativa, política o sindical) se pone a disposición desinteresada de la comunidad, promoviendo la solidaridad. Para ello ofrece energías, capacidades, su tiempo y, eventualmente, los medios de que dispone, como respuesta creativa a las necesidades emergentes del territorio y, prioritariamente a aquéllas que corresponden a los marginados. Todo ello, preferiblemente, mediante la acción de un grupo que suministre la formación permanente y la continuidad del servicio en colaboración con las instituciones públicas y las fuerzas sociales".

En los últimos años un tipo de voluntariado social que está emergiendo con gran fuerza es el voluntariado corporativo, que nace desde el ámbito empresarial. Este tipo de voluntariado es definido por CSR Europa, organización de referencia en Europa en materia de RSC, como "aquellas actividades donde los trabajadores de una empresa ponen al servicio de la comunidad sus habilidades y tiempo para afrontar temáticas sociales y ambientales".

El voluntariado corporativo organizado y dirigido desde la propia empresa u organización como una práctica de RSC dirigida hacia la sociedad en general. Esta práctica de RSC es implementada a través de los denominados programas de voluntariado corporativo definidos por Sanz, et al. (2012) como "programas promovidos por la empresa dirigidos a incentivar y apoyar a sus empleados para que desarrollen de forma desinteresada acciones solidarias en favor de la comunidad, generalmente a través de una organización social.... Pueden estar externalizados a través de entidades sociales colaboradoras o ser desarrollados por la propia empresa o por una fundación de esta". Un ejemplo de este tipo de práctica corporativa es la llevada a cabo en la empresa pública "Metro de Madrid, S.A" que enseña a un grupo de jóvenes autistas a desplazarse de forma autónoma por la red. Metro de Madrid cuenta con un programa de voluntariado corporativo orientado a la realización de visitas por personas con distintas capacidad. Empleados de la empresa acompañan a jóvenes para que se familiaricen con la red de Metro, fomentando así su autonomía, al mismo tiempo que conocen de primera mano el día a día de los trabajadores de Metro y compartan con ellos una jornada de ocio inclusivo ${ }^{1}$.

Por lo tanto, y haciendo un breve repaso histórico, exponemos que el desarrollo del voluntariado en España posee algunas características diferenciales con respecto a los países más cercanos a nuestro entorno. Mientras que en otros países europeos, después de la Segunda Guerra Mundial, se desarrolla el Estado de Bienestar, durante el período dictatorial en España la participación de las asociaciones y del voluntariado, se ve más restringida.

Un hecho significativo para el asociacionismo se sitúa en la promulgación de la Ley de asociaciones de 1964, en pleno desarrollismo económico. Del mismo modo, la Constitución Española de 1978 marca un antes y un después en todos los ámbitos y también en el plano social. Se configura un nuevo marco político desarrollado a través del sistema democrático de economía de mercado que va configurando el denominado Estado de Bienestar. (Tavaz- 
za, 1995).

Pero, sin duda, un pilar significativo para el voluntariado en esta época es la promulgación de las Leyes Autonómicas de Servicios Sociales, y en su artículo 148.20 de la Constitución otorga la competencia de Servicios Sociales a las CC.AA. Desde 1982 a 1992 surgen estas leyes autonómicas que contemplan en su articulado el reconocimiento del Voluntariado, como acción complementaria y fundamental en la intervención de los servicios sociales.

En este sentido, y siguiendo a (Grandal Nores, 1994), la evolución del voluntariado en España queda caracterizado por las siguientes etapas:

Años 40 y 50: El régimen político deja poco espacio al trabajo voluntario que no sea el desarrollado a través de:

1. Organizaciones dependientes de la Iglesia

2. Organizaciones ligadas al régimen político

3. Voluntariado marcadamente asistencialista y de componente ideológico

Años 60: Se inicia un despegue económico que conlleva cambios sociales significativos:

1. La Ley de Asociaciones de 1964 supone un paso importante

2. El Estado empieza a asumir funciones de asistencia social y a crear servicios de este tipo en la Administración Central y Periférica

3. Se debilitan las organizaciones de carácter social vinculadas al régimen político, pasando muchas de ellas a la Administración del Estado

4. Las organizaciones vinculadas a la Iglesia se adaptan a los cambios

5. Surgen nuevas organizaciones de carácter privado y sin ánimo de lucro, en defensa de intereses sociales, específicos y de grupo

Finales del 60 al 79: La vida asociativa se manifiesta con carácter reivindicativo, aunque discreta en su mayoría. Ejemplos de ello son:

1. Asociaciones de Afectados

2. Plataformas reivindicativas

3. Interlocutores válidos

4. Asociaciones Ciudadanas, etc.

5. Constitución Española de 1978. Se abre una nueva etapa

Años 80: Se expande la participación ciudadana:

1. Se acrisola la acción social de organizaciones y asociaciones de todo tipo

2. Muchos líderes de la acción voluntaria pasan a la militancia política y sindical a raíz de la apertura democrática

3. Aparecen nuevos movimientos sociales, reivindicativos, hacia la con- quista de logros de carácter legal y de una mayor calidad de vida

4. Leyes autonómicas de Servicios Sociales. Reconocimiento del Voluntariado

5. Ingreso en la Comunidad Económica Europea. 1986

6. Desarrollo del Voluntariado en general

7. Creación de Plataformas Nacionales, Provinciales, etc. de Voluntariado y representación en Organismos Internacionales

Años 90: Se generaliza el reconocimiento oficial del Voluntariado Social por la Administración: 
1. La Administración Local se interesa en establecer lazos de cooperación

2. Creación de Institutos de Voluntariado y Direcciones Generales de Acción Cívica en Departamentos de Bienestar Social.

3. Leyes autonómicas especificas para el Voluntariado

4. Es el momento del Voluntariado Social Estatutario

En el Siglo XXI, la globalización y la era digital están cambiando los rostros del voluntariado. Esta transformación es difícil y se ha cuestionado de forma crítica el valor y las contribuciones de muchas de las formas nuevas que adopta este fenómeno. En algunos casos, el voluntariado basado en la tecnología puede suplantar la participación voluntaria significativa y relevante. En consecuencia, es preciso realizar esfuerzos para asegurar la máxima participación de todos los miembros de la sociedad. Del mismo modo, es importante tener en cuenta que no es Voluntariado Social:

- Las prácticas profesionales para acceder a un puesto de trabajo, ya que esto choca con el carácter desinteresado del voluntariado, y con el derecho de las personas que se benefician a no servir de campo de experimentación para profesionales que comienzan.

- La mano de obra barata, porque el voluntariado no debe sustituir a los/las profesionales.

- Los actos benevolentes, esporádicos, realizados por razones familiares, de amistad o buena vecindad, por no ser continuados ni estar organizados.

- El "voluntariado" en empresas, porque esto esconde en muchas ocasiones prácticas laborales poco éticas².

La Plataforma Estatal del Voluntariado ${ }^{3}$ estima que en 2013 el número de ciudadanos en España que realiza alguna labor social de forma altruista se ha incrementado un 20 por ciento y ya supera los cinco millones, pese a los recortes económicos que, según afirman "ponen en riesgo muchas de las tareas que vienen desarrollando".

En cuanto a los voluntarios en sí, la Plataforma señala, con datos de su Observatorio del Voluntariado, que el perfil mayoritario sigue siendo femenino (59\% de mujeres frente a $41 \%$ de hombres) y las edades más activas, las comprendidas entre menores de 30 y mayores de 55 .

Quizás la contribución más importante del voluntariado a nuestra sociedad pasa por la creación de capital social, lo que genera efectos positivos en la eficacia de las instituciones democráticas, coadyuvando a la solución de los problemas colectivos y en el desarrollo económico. El voluntariado dota a la sociedad de una capacidad de gestión y de influencia en el que crece la democracia política, extendiendo esta democracia a otras parcelas diferentes de las del poder.

\section{Voluntariado en ONGS y ONG de desarrollo (ONGD). Algunos conceptos básicos}

\section{Organizaciones No Gubernamentales (ONG)}

Según la organización de las Naciones Unidas (ONU) una Organización No Gubernamental es la formada por "cualquier grupo de ciudadanos voluntarios sin ánimo de lucro que surge en el ámbito local, nacional o internacional, de naturaleza altruista y dirigida por personas con un interés en común”. Una organización no gubernamental (también conocida

\footnotetext{
2 En este sentido véase: Introducción al Voluntariado Social. Junta de Andalucía (2014) Disponible en: http:// www.juntadeandalucia.es/organismos/igualdadsaludypoliticassociales/areas/inclusion/voluntariado-social/paginas/introduccion-voluntariado.html.

3Para más información véase la plataforma estatal del voluntariado (2014): Disponible en http://www.europapress.es/epsocial/ong-y-asociaciones/noticia-mas-millones-personas-hacen-voluntariado-espana-20-mas2012-plataforma-estatal-20131205145754.html
} 
por las siglas ONG) la podemos entender como una asociación de carácter civil concebida como" el derecho y la disposición de participar en una comunidad, a través de la acción autorregulada, inclusiva, pacífica y responsable, con el objetivo de optimizar el bienestar público o social", con diferentes fines integrantes, creada independientemente de los gobiernos ya sea locales, regionales y nacionales, así como también de organismos internacionales. (Pineda, 1999).

En los últimos años ha proliferado el número de ONGs como instituciones de referencia ética en la sociedad; este reconocimiento es además fundamental para la supervivencia de éstas, pues gran parte del capital humano y financiamiento de la organización depende de la ayuda desinteresada de donantes (administración pública y particulares) y voluntarios. De acuerdo con la legitimidad de las ONGs, cabe señalar que ésta no es permanente, más bien depende de una adecuada transparencia que muestre que los objetivos de la organización no sólo benefician a unos pocos, sino que persiguen fines de carácter plural. La elaboración de información no sólo es necesaria para la toma de decisiones, sino que es fundamental para responder a las necesidades informativas de los principales grupos de interés (donantes, gobiernos y beneficiarios) de las ONG. La transparencia de las ONG es el grado de información y la actitud en que se afronta la rendición de cuentas. (Medina, 2009).

Entre los mecanismos de rendición de cuentas que aplican las $\mathrm{ONG}$, autores como (O’rourke, 2006) y (Argandoña, 2007) señalan los códigos de conducta que son procesos de carácter voluntario que comprenden una serie de valores para la adecuada gestión interna y externa de la organización. Estos códigos de conducta contribuyen al éxito de la misión de las ONG y al incremento de la participación de los grupos de interés.

\section{Organizaciones No Gubernamentales de Desarrollo (ONGD)}

El desarrollo puede concebirse como un proceso de expansión de las libertades reales que disfrutan los individuos, contribuyendo al mejoramiento de sus capacidades generales (Sen, 2000). Este autor resalta las libertades políticas, los servicios económicos, las oportunidades sociales, las garantías de transparencia y la seguridad protectora, siendo todas ellas prioridades para las ONG.

Continúa (Pineda, 1999) afirmando que las ONG presentan un importante aporte para el desarrollo en áreas como ambiente, derechos humanos, promoción comunitaria, desarrollo económico y promoción política; además se han convertido en una importante fuente de trabajo: primero para ciertos grupos de profesionales dentro del marco de organizaciones de contratación pública, y segundo con acciones de desarrollo dirigidos a generar y mejorar el empleo y los ingresos en el sector informal; mediante programas de microempresas.

En los últimos años se han producido cambios importantes en el ámbito de la Cooperación al Desarrollo. La sociedad ha vuelto sus ojos hacia el mundo de la solidaridad. Los diferentes agentes que están jugando algún papel en este campo han visto cómo su influencia y su presencia en la sociedad se han incrementado notablemente.

De hecho, durante el año 2011, más de 1.850 .000 personas y entidades han apoyado de forma estable y periódica a las ONGD españolas y más de 575.000 lo han hecho de forma puntual, mientras que la colaboración con las entidades privadas ha dado lugar a más de 800 convenios y patrocinios ${ }^{4}$.

Las ONGD, como expresión de la solidaridad existente en la sociedad, juegan un papel importante en el ámbito de la cooperación internacional precisamente por ser la sociedad la que asigna este cometido. Al asumir este papel, es importante clarificar algunos conceptos

4 Para más información véase: Informe de la Coordinadora de ONGD en España sobre el sector de las ONGD (2011). Disponible en: http://informe2011.coordinadoraongd.org/uploads/Informe_Anual_de_la_Coordinadora_ONGD_2011.pdf 
y consensuar algunos principios, dada la multiplicidad y pluralidad de organizaciones que existen. Por lo tanto deben ${ }^{5}$ :

- Promover el desarrollo, entendiéndolo como un proceso de cambio social, económico, político, cultural, tecnológico, etc... que, surgido de la voluntad colectiva, requiere la organización participativa. El desarrollo, así entendido, crea condiciones de equidad que abren más y mejores oportunidades de vida al ser humano para que despliegue todas sus potencialidades.

- Luchar por erradicar la pobreza concebida como la situación de privación de los elementos esenciales para que el ser humano viva y se desarrolle con dignidad física, mental y espiritual, teniendo en cuenta sus necesidades en relación con el género, las capacidades, los valores culturales, la edad y el grupo étnico.

- Considerar que la pobreza es, fundamentalmente, resultado de la explotación de los pueblos y de la naturaleza. Y que la causa de las desigualdades sociales está en el acceso desigual a los recursos y en la exclusión de los pueblos de la toma de decisiones que les atañen.

- Ejercer la cooperación con los pueblos del Sur, entendiendo que ésta es un intercambio entre iguales, que pretende fomentar el desarrollo y lograr la erradicación de la pobreza. La cooperación es una actividad que es preciso ubicar en el contexto de las relaciones internacionales y, por lo tanto, mantiene una estrecha relación con el resto de políticas Norte-Sur, sobre las que pretende influir sin limitarse al ejercicio de una simple financiación.

- Otorgar una gran importancia a otros aspectos que informan decisivamente sobre su pensamiento y acción, tales como; la igualdad de género, el respeto al medio ambiente y la promoción de los derechos humanos.

Del mismo modo, el concepto de género designa lo que en cada sociedad se atribuye a cada uno de los sexos, es decir, se refiere a la construcción social del hecho de ser mujer u hombre, a la interrelación entre ambos y las diferentes relaciones de poder/subordinación en que estas relaciones se presentan.

Siguiendo a (Murgialday, 2006, p. 15) el concepto de género también se puede definir como:

"categoría que subraya la construcción cultural de la diferencia sexual, esto es, el hecho de que las diferentes conductas, actividades y funciones de las mujeres y los hombres son culturalmente construidas, más que biológicamente determinadas".

El sistema y las relaciones de género afectan a todas las relaciones sociales, definiendo los diferentes roles, comportamientos, actitudes y valores que son internalizados por mujeres y hombres en sus procesos de socialización. El actual sistema de género coloca a las mujeres en posición de inferioridad y subordinación, haciendo de las relaciones de género una dimensión de desigualdad social.

Por lo tanto, las ONGD deben tener por objetivo, entre otros, crear las condiciones para que las mujeres, como miembros de la comunidad, participen en la toma de decisiones. Así como promover su incorporación activa en todos los programas de desarrollo y ayuda humanitaria, para asegurar el acceso y control equitativo a los recursos y beneficios de los mismos.

5 En este sentido véase: AA.VV (2012). Manual de Formación de Voluntarios: Cultura de la Solidaridad y Voluntariado (2012). Disponible en http://www.bidelagun.com/wp-content/uploads/voluntariadosalamanca.pdf 


\section{La cooperación internacional para el desarrollo}

Entendemos por Cooperación Internacional para el Desarrollo, al conjunto de actuaciones, realizadas por actores públicos y privados, entre países de diferente nivel de renta con el propósito de promover el progreso económico y social de los países del Sur, de modo que sea más equilibrado en relación con el norte y resulte sostenible.(Gómez y Sanahuja, 1999).

La Cooperación para el Desarrollo tiene como característica ineludible su gratuidad por lo tanto no cualquier forma de financiación que promueva el desarrollo debe considerarse cooperación al desarrollo, no toda financiación pública es considerada Ayuda Oficial al Desarrollo.

La Ayuda Oficial al Desarrollo, en adelante AOD, son las corrientes, los flujos de recursos y conocimientos que se destinan a los países (ayuda bilateral) y a las instituciones multilaterales (ayuda multilateral) que figuran en la "Lista de Países Receptores del Comité de Ayuda al Desarrollo" y en la "Lista de Organismos Multilaterales" y que son proporcionados por organismos oficiales. Dentro de la AOD podemos diferenciar varios tipos de ayuda:

1. La ayuda de emergencia que consiste en la ayuda proporcionada a las víctimas de desastres con carácter de urgencia; es una ayuda cortoplacista destinada a socorrer a la población.

2. La ayuda humanitaria que incluye un campo más amplio que abarca además de los bienes y servicios básicos para la subsistencia la protección de las víctimas y sus derechos fundamentales; generalmente se trata de ayuda a poblaciones para conseguir su subsistencia pero que no persigue el desarrollo de las poblaciones pues el mismo es imposible por el entorno y circunstancias existentes (por ejemplo, población desplazada o campos de refugiados).

3. La Educación al Desarrollo es un ámbito que pretende la implicación de la ciudadanía en el compromiso de la lucha contra la pobreza y la exclusión social y con el desarrollo humano y sostenible a través de la sensibilización, la formación sobre el Desarrollo, la investigación para el desarrollo y la movilización social. Junto a todos ellos están los proyectos y programas de cooperación al desarrollo (gestionados directamente por el Estado español o de manera indirecta a través de ONGDs, sindicatos, universidades, fundaciones, etc).

Por lo tanto, como indica (Alonso, 1999) si el concepto de cooperación utilizado se traduce en la expresión operativa de un principio básico de convivencia en el mundo actual, entendido como el compromiso de los ciudadanos con el conjunto de los habitantes del planeta, con su situación presente y con su futuro (Alonso et al., 1999, p.399), permite incluir como actor principal de la cooperación a la sociedad civil, con lo cual cobran importancia otros instrumentos de la cooperación como son la sensibilización y educación para el desarrollo, la investigación, el comercio justo y la presión política.

\section{Estructura del sistema público de cooperación para el desarrollo}

La política de cooperación al desarrollo española es más joven que la de países de nuestro entorno, debido a un desarrollo económico reciente, y a otros condicionantes históricos. España pasa de ser receptor a donante de ayuda en un plazo de tiempo breve. Marcar el inicio de la cooperación al desarrollo en España no es sencillo, aunque podemos establecerlo en 1983 cuando solicita salir definitivamente de la lista del CAD de países receptores de AOD (González Badía y Ruiz Seisdedos, 2004).

La instancia política responsable de la cooperación no se creará hasta mediados de los años ochenta: la Secretaría de Estado para la Cooperación Internacional y Para Ibero América (SECIPI), encuadrada dentro del Ministerio de Asuntos Exteriores. A partir de ese mo- 
mento se irá creando, paulatinamente, el resto de estructuras y organigramas de la cooperación española.

El sistema institucional adquiere pleno desarrollo con la creación en noviembre 1988 de la Agencia Español de Cooperación Internacional (AECI), principal órgano ejecutor de la política española de cooperación para el desarrollo, encargado de la gestión de la cooperación no reembolsable.

En 1991 finaliza el proceso de incorporación de España al sistema internacional de ayuda y cooperación al desarrollo, al adherirse al Comité de Ayuda al Desarrollo (CAD) de la OCDE.

Será en esta década de los 90 en la que las ONG comienzan a participar de forma masiva en el ámbito de la cooperación que hasta este momento estaba en manos casi exclusivamente de los gobiernos. La figura del voluntariado comienza a ser habitual en el marco de una cooperación no gubernamental cuyos actores principales son estructuras de la sociedad civil. Sin embargo, en los últimos años, el voluntariado se está profesionalizando y en el ámbito de la cooperación internacional trabajan personas con una formación técnica especializada, quedando la figura de la persona voluntaria surgida en los 90 más cercana a prácticas de solidaridad comunitaria.

El sistema español de cooperación al desarrollo está hoy en día organizado según lo establecido en la Ley 23/1998 y en su desarrollo reglamentario. Esta Ley de Cooperación, la primera en tal sentido en nuestro país, nos ha permitido gozar de una referencia legal hasta ahora inexistente.

La estructura organizativa se sigue mostrando ciertamente compleja por la profusión de órganos y comisiones creados. Hay dos departamentos de la Administración General con especial protagonismo en el área de dirección y ejecución, aun cuando no son los únicos ministerios con capacidad para desplegar acciones de cooperación internacional para el desarrollo, son: el Ministerio de Exteriores y Cooperación y el de Economía y Hacienda, canalizando entre ambos cerca del 70\% de la AOD. El resto de Ministerios realiza actividades de cooperación que representan un margen menor (8-10\%), siendo el 15\% restante gestionado por los entes descentralizados ${ }^{6}$.

El Ejecutivo es el encargado de la dirección de la política exterior y de cooperación internacional, mediante sus distintos departamentos, garantiza la presencia de España en los distintos organismos y foros internacionales, en los que se debaten materias relacionadas con la cooperación y el desarrollo.

El Parlamento establece cada cuatro años las líneas generales de la política de cooperación a propuesta del Gobierno. También debate y dictamina sobre el Plan Anual.

\section{Ministerio de Asuntos Exteriores y Cooperación}

El Ministerio de Asuntos Exteriores y Cooperación (MAEC) es el responsable de la dirección política de la cooperación para el desarrollo y de la coordinación del resto de ministerios implicado, tal y como señala el artículo 17 de la Ley 23/1998.

Quien asume directamente las tareas de dirección y coordinación en el área de la cooperación al desarrollo es la Secretaría de Estado de Cooperación Internacional y para Iberoamérica (SECIPI). Esta Secretaría gestiona la mayor parte de la AOD no reembolsable, bilateral, multilateral y las subvenciones a ONGDs, la evaluación de la política de cooperación para el desarrollo, etc.

La Cooperación Española se ha dotado de una serie de órganos consultivos y de coordinación cuyo objetivo es facilitar la coherencia de las acciones y la coordinación entre los distintos actores de la Cooperación Española. Estos órganos son el Consejo de Cooperación al Desarrollo, la Comisión Delegada del Gobierno para la Cooperación al Desarrollo, la

6 Este porcentaje va variando según los años y es meramente orientativo. 
Comisión Interministerial, la Conferencia Sectorial y la Comisión Interterritorial de Cooperación para el Desarrollo.

\section{La Agencia Española de Cooperación Internacional para el Desarrollo}

Esta agencia se establece como un organismo autónomo adscrito al Ministerio de Asuntos Exteriores, a través de la Secretaria de Estado de Cooperación Internacional. El esquema general de mando sería (SECIPI - Secretaria General - AECID). En líneas generales, podemos decir que es el órgano técnico responsable del diseño, la ejecución y la gestión de los proyectos y programas de cooperación, ya sea directamente, con sus propios recursos, o bien mediante la colaboración (convenios, acuerdos) con otras entidades nacionales e internacionales y organizaciones no gubernamentales. La AECID es igualmente la responsable de la ayuda humanitaria, de emergencia y la alimentaria, que se gestionan desde unidades especializadas, al igual que del programa de subvenciones y cofinanciación de proyectos con ONGDs. Ejerce la superior dirección de la Oficina de Acción Humanitaria y de la Oficina del Fondo para la Promoción del Desarrollo. La estructura exterior está compuesta en la actualidad por 37 Oficinas Técnicas de Cooperación $\left(\mathrm{OTC}^{7}\right), 12$ Centros Culturales y 3 Centros de Formación en los países con los que la AECID lleva a cabo sus principales proyectos de cooperación.

\section{Instrumentos de planificación de la cooperación española}

En los últimos años la cooperación española está creando diversos mecanismos de planificación, seguimiento y evaluación de las distintas actividades que lleva a cabo con el fin de mejorar el impacto de las mismas.

Uno de los instrumentos básicos para la planificación de la AOD española lo constituyen los Planes Directores de la Cooperación Española (MAEC, 2001-2016). Tienen carácter cuatrienal y en la actualidad está vigente el tercero. El primer Plan Director de la Cooperación Española corresponde a los años 2001-2004, los siguientes son de los años 2005-2008, 2009-2012 y el actualmente vigente a los años 2013-2016. En el mismo se establecen las prioridades horizontales, sectoriales y geográficas de la Cooperación española, instrumentos y recursos.

Los Planes Anuales de Cooperación Internacional (PACI) (MAEC, 1998-2014) desarrollan los objetivos, prioridades horizontales, sectoriales y geográficas, los actores de la cooperación que intervienen y las previsiones de ayuda. Anualmente también se publican los Seguimientos de los PACI que evalúan y realizan un seguimiento de la ejecución de los programas y proyectos aprobados y recogidos en los PACIs. En este sentido describen las actuaciones que han realizado las diferentes entidades públicas españolas anualmente y los recursos que han utilizado para su ejecución.

En la planificación se incluyen además las Estrategias sectoriales: señalan las directrices y lineamientos de la cooperación española en determinados sectores. Las Estrategias horizontales: establecen las prioridades horizontales de la cooperación española. Además se establece la planificación geográfica a través de los Marcos de Asociación País (MAP) para los países prioritarios señalados en el Plan Director, estos MAP sustituyen a los antiguos Documentos Estrategia País (DEP) y Planes de Actuación Especial (PAE): que establecían para cada país los objetivos y líneas estratégicas de los países prioritarios y o preferentes o de actuación especial, respectivamente.

7 Las OTCs son las encargadas de aplicar los programas y proyectos de cooperación de cualquier Administración, concertarse con las autoridades del país receptor y hacer el seguimiento de la evolución y coordinar con las administraciones (autonómicas y locales) y los demás agentes de la cooperación la elaboración de los documentos estratégicos del país en todas las fases de gestión del ciclo de las Intervenciones de desarrollo 
Presupuesto, distribución y prioridades

A continuación vamos a realizar un análisis somero de los recursos destinados a AOD y su evolución (gráficos 1 y 2). A nivel general podemos observar un aumento constante en términos absolutos en la AOD española desde sus inicios, aunque son evidentes los recortes en el volumen de la AOD sufridos en los últimos años.

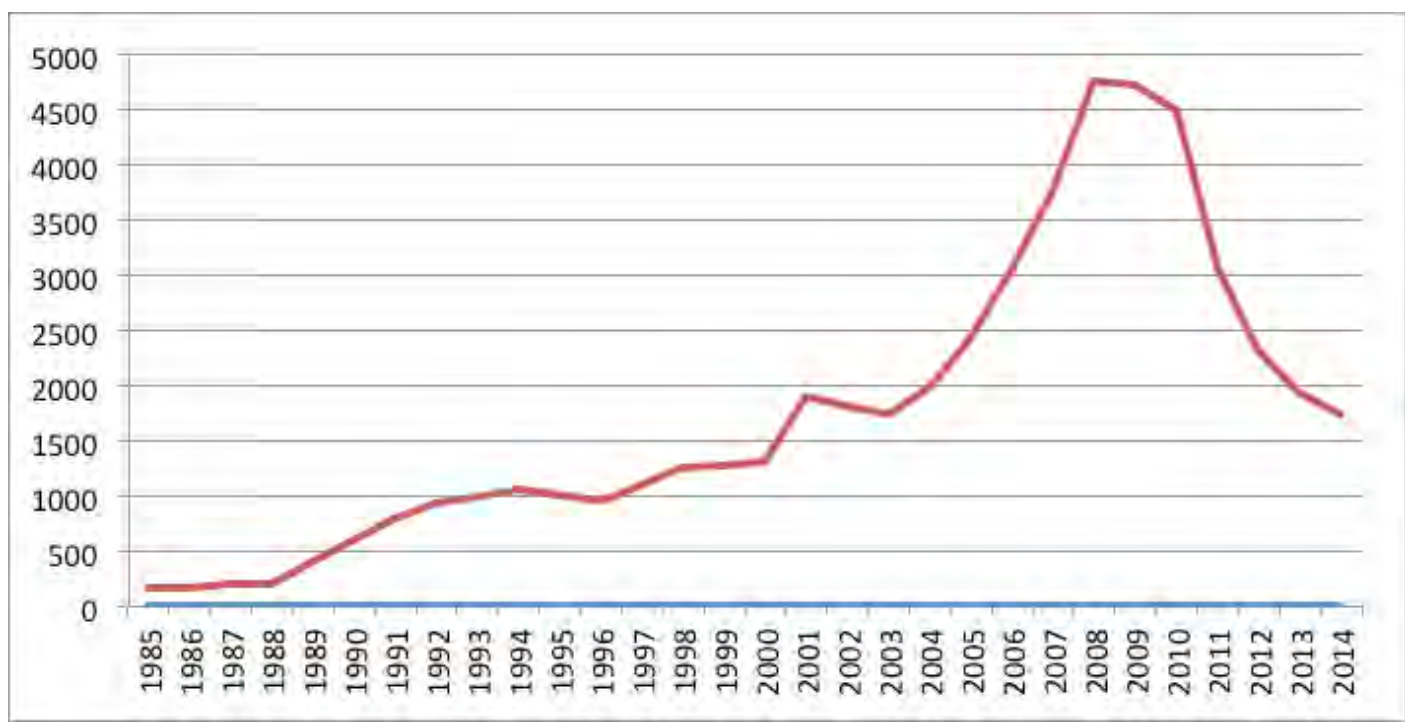

Gráfico 1. Evolución de la AOD neta española (1985-2012). En millones de euros (Fuente: Elaboración propia a partir de PACI y PACI Seguimiento 1998-2014).

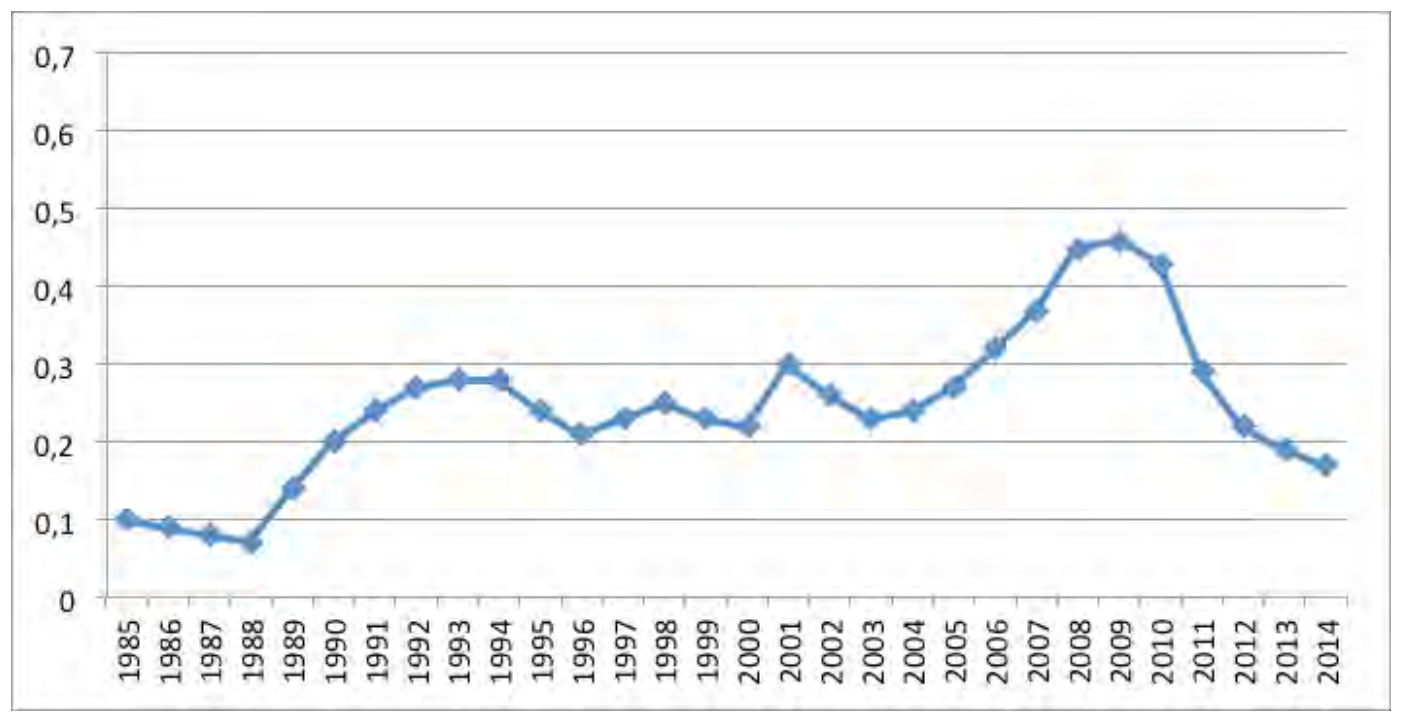

Gráfico 2. Evolución de la AOD neta española (1985-2012). En \% AOD/RNB (Fuente: Elaboración propia a partir de PACI y PACI Seguimiento 1998-2014. *Previsiones). 
En líneas generales, podemos afirmar que alrededor del 90\% de la AOD española está dirigida a Cooperación para el Desarrollo, siendo un porcentaje pequeño el que se dedica a la Acción Humanitaria (alrededor del 5-8\%) y mucho menor a Educación para el Desarrollo y Sensibilización (entre el 1 y $2 \%$ ).

\section{Distribución Geográfica}

Tradicionalmente las prioridades geográficas de la cooperación española han sido los países latinoamericanos y del norte de África. Así se recoge en la Ley de Cooperación Internacional para el Desarrollo, en su artículo 6.

Se ha producido una importante evolución en el número y los países prioritarios de la cooperación española, aunque el CAD crítica que se produce una marcada dispersión de esfuerzos, pues son un número excesivo de países los que reciben ayuda.

Por zonas geográficas, América Latina es la principal receptora, recibiendo siempre más del $30 \%$ de los recursos, seguido por África que en los últimos años se acerca mucho a los fondos destinados a Latinoamérica. El resto de zonas está muy lejos de las anteriores.

\section{Distribución sectorial}

Son diversas las clasificaciones que podemos efectuar sobre los sectores a los que destinamos nuestra ayuda. La ley establece una, los planes directores otra y el CAD realiza la suya propia.

El sector de Infraestructuras y servicios sociales es al que más fondos se destinan, casi el 50\% del total. Gobierno y sociedad civil junto con Educación y Abastecimiento y depuración de aguas son los subsectores con más fondos adjudicados.

\section{La cooperación descentralizada}

La cooperación descentralizada o Cooperación Oficial Descentralizada se define como aquella clase de cooperación que realizan o promueven los poderes descentralizados o locales, es decir, los Ayuntamientos, Diputaciones Provinciales, y Gobiernos Autonómicos, exclusivamente, ya sea de modo directo o indirecto, esto es, acudiendo para la ejecución de los proyectos a las entidades de la sociedad civil, como son las ONGDs, fundaciones, asociaciones, universidades, centros de investigación, partidos políticos o sindicatos. La cooperación descentralizada tiene un fuerte carácter local o territorial y en ella prima la participación de todos los agentes que están implicados en este proceso, pero este planteamiento no es sustitutorio del tradicional (la cooperación promovida por los gobiernos) sino complementario. Se caracteriza por la procedencia de los recursos, por su voluntad de participar en proyectos de desarrollo humano en los que la aportación popular sea un elemento central, así como por su vocación de promover el desarrollo local y dar un impulso a las organizaciones para la colaboración ciudadana y la democracia participativa.

Los Fondos de cooperación surgen a mediados de los ochenta y tienen como finalidad principal la coordinación de las aportaciones de los entes locales de una determinada comunidad autónoma. Los Fondos son los actores más originales y novedosos, destacando por la importancia de los recursos que manejan, la coordinación que llevan a cabo, su tarea de impulso de la cooperación, la ayuda técnica que prestan a las municipalidades, etcétera. En la actualidad, los Fondos existentes son el Fons Catalá, EuskalFondoa, Fons Valenciá, Fondo Andaluz de Municipios por la Solidaridad Internacional (FAMSI), FonsPitius, FonsMallorquí, FonsMenorquí, Fondo Extremeño, Fondo Galego ${ }^{8}$. 


\section{Algunas conclusiones}

Cuando hacemos alusión al término voluntariado lo entendemos como una actitud que busca construir una sociedad sin exclusión o marginación, en la que las personas sean respetadas como seres humanos y sean partícipes, en condiciones de igualdad, en la solución de los problemas y en la creación de alternativas para una convivencia pacífica, siendo un instrumento fundamental para el desarrollo de la ciudadanía, en la consideración de que únicamente de este modo se puede conseguir una democracia plena y participativa.

Del mismo modo, un gran número de ONGs han surgido con el propósito de atender y satisfacer necesidades sociales utilizando programas y acciones que el Estado no ha logrado cumplir y que el sector privado no está interesado en intervenir.

Las ONG no sólo son autónomas e independientes de los gobiernos, lo que les permite convertirse en actores influenciadores de la política pública, sino que también cumplen la función de mecanismo de participación política, rol cada vez más importante en la promoción de la democracia.

A este tenor, en la dimensión social, las ONGs se definen como instituciones intermedias entre las instituciones gubernamentales y los individuos, que se constituyen voluntariamente para satisfacer necesidades sociales y culturales mediante aportaciones de esfuerzos humanos, donde son prioridades entre otras, la participación de la sociedad en la construcción de la política pública, la adquisición igualitaria de los servicios económicos, el incremento de las oportunidades sociales, el aumento de las garantías de transparencia y la seguridad protectora para la sociedad.

Por lo anterior las Organizaciones No Gubernamentales para el Desarrollo (ONGD) tienen una relación directa, al ser las primeras, generadoras de éstas.

En el marco de la cooperación internacional al desarrollo conviven profesionales y voluntarios, que tienen que andar un mismo camino con funciones diferentes y que muchas veces se entremezclan. Este es un debate que se plantea en la acción social y que es necesario abordar. La profesionalización del mundo de la cooperación responde a la necesidad de coordinar, organizar los recursos para responder más eficazmente a las necesidades de la población, sin embargo el voluntariado ha de buscar necesariamente una dimensión cívica y ha de buscar también la incidencia política, dado que ambos aspectos están estrechamente relacionados con su vocación transformadora. La dimensión política, no conlleva adscripción política partidista, sino compromiso con una participación activa en los asuntos políticos que afectan al conjunto de la ciudadanía y que en consecuencia están en la base de las cuestiones de las que se ocupa el voluntariado y nunca como sostenimiento de las organizaciones para poder llevar a cabo sus proyectos y acciones sino como transformador y creador de conciencia crítica en el desarrollo comunitario, partícipe e impulsor de una ciudadanía crítica y responsable.

\section{Bibliográfia}

AA.VV (2012). Manual de formación de voluntarios: Cultura de la solidaridad y voluntariado. Disponible en http://www.bidelagun.com/wp-content/uploads/voluntariadosalamanca.pdf AA.VV (2000): La cooperación Descentralizada para el Desarrollo Humano. La contribución española a un debate internacional, Madrid, AIETI e ICEI.

Argandoña, A. (2007). Ethical management sistems for not for profit organizations. IESE-Business School University of Navarra.

CAD-OCDE (1998). Serie de exámenes en materia de cooperación al desarrollo: España, Paris, OCDE.

Coordinadora de ONGD (2011). Informe de la coordinadora de ONGD en España sobre el sector de las ONGD. Publicaciones Coordinadora. Disponible en: http://informe2011.coordinadoraongd.org/uploads/Informe_Anual_de_la_Coordinadora_ONGD_2011.pdf 
FEMP (2005, 2006, 2007, 2008). Informe de Cooperación de Entidades Locales, Madrid. Disponible en http://cooperacion.femp.es/index.php/documentacion

García-Rincón de Castro, C. (2003). Cuaderno de Viaje para Acompañar Experiencias de Voluntariado Social. Madrid: Ediciones Homo Prosocius.

Gonzalez-Badia, J., Ruiz, S. (2004). La cooperación al desarrollo: un reto para los entes descentralizados. Granada. Ediciones: Unión Iberoamericana de Municipalistas.

Grandal, I (1994). Voluntariado Social y Servicios Sociales, Revista de Trabajo Social y Servicios Sociales. Colegio Oficial de Diplomados en Trabajo Social de Santiago de Compostela, 25, 21-29.

Grasa, R (2002). Instituciones para una cooperación al desarrollo de calidad: aclaraciones y propuestas iniciales, Revista CIDOB D'Afers Internacional, 72(4), 254- 263.

Intermon Oxfam (2003, 2012), La realidad de la ayuda: una evaluación independiente de la ayuda internacional. Barcelona: Intermón Oxfam.

Ley 23/1998 De Cooperación Internacional Para El Desarrollo.

Ministerio de Asuntos Exteriores y Cooperación-MAEC (1998-2014). Plan Anual De Cooperación Internacional (Previsiones y Seguimiento) 1998 a 2014. Madrid, Ministerio de Asuntos Exteriores y Cooperación. Disponible en: http://www.aecid.es/web/es/publicaciones/Documentos/paci/

Ministerio de Asuntos Exteriores y Cooperación-MAEC (2001-2016). Plan Director De La Cooperación Española 2001-2004, 2005-2008, 2009-2012, 2013-2016. Madrid, Ministerio de Asuntos Exteriores y Cooperación. Disponible en: http://www.aecid.es/web/es/publicaciones/Documentos/Plan_director/

Martínez, I. y Sanahuja, J.A. (2010): La agenda internacional de eficacia de la ayuda y la cooperación descentralizada en España, Madrid, Fundación Carolina, Documento de Trabajo $\mathrm{n}^{\mathrm{o}}$ 38. Disponible en: http://www.fundacioncarolina.es/esES/publicaciones/documentostrabajo/Documents/DT38.pdf

Medina, J. (2009). Transparencia y buen gobierno en las ONGD. Revista Española del Tercer Sector. 7 (8): 93-113.

Molina, I.; Olivi, Iliana y Steninberg, F. (2012): La reorganización de la acción exterior española por el nuevo gobierno del Partido Popular. Madrid, Real Instituto Elcano. Disponible en:http://www.realinstitutoelcano.org/wps/portal/rielcano/contenido?WCM_GLOBAL_ CONTEXT=/elcano/elcano_es/zonas_es/ari9-2012

Murgialday, C. (2006): Diccionario de acción humanitaria y cooperación al desarrollo. Bilbao: Ediciones Icaria-Hegoa.

Nieto Pereira, L. (2001): Cooperación para el desarrollo y ONG: una visión crítica, Madrid, Instituto Universitario de Desarrollo y Cooperación de la UCM.

O'Rourke, D (2006). Multi-stakeholder regulation: privatizing or socializing global labor standards? Worlddevelopment. 5 (2): 899-918.

Pérez de Armiño, K. (2006): Diccionario de acción humanitarias y cooperación al desarrollo, Bilbao, Icaria-Hegoa, 2006 Disponible en: http://www.dicc.hegoa.ehu.es

Pineda, J. (1999). Las organizaciones sin ánimo de lucro para el desarrollo: Una revisión de su inserción en el concepto de sociedad civil en Colombia. Revista Innovar, 13: 121-129.

Rodríguez A (1993): La descentralización y la izquierda latinoamericana. Managua: Ediciones Fundación Friedrich Ebert.

Ruiz Seisdedos, S. (2008): La cooperación descentralizada, un nuevo modelo de desarrollo: Análisis de las relaciones España-Nicaragua. Historia Actual Online, 15 (invierno): 107-120. Disponible en: http://www.historia-actual.org/Publicaciones/index.php/haol/article/viewFile/236/224

Sanz, B. (2012). El voluntariado corporativo en España. Modelos y perspectivas de impacto social. Madrid: Ediciones ESADE.

Sen, A. (2000). Desarrollo y Libertad. Santafé de Bogotá: Ediciones Planeta

Tavazza, L. (1995). El nuevo rol del voluntariado social. Madrid: Ediciones Lumen.

Tavazza, L. (1995): Innovación y reglamentación en la política social. La solidaridad dentro de un sistema complejo en VV.AA.: El Voluntariado, Fundació Bancaixa. Pp.26-27, Valencia. 1995. 
UN Voluntarios (2011). Informe sobre el estado del voluntariado en el mundo: El voluntariado en el siglo XXI. Programa de las Naciones Unidas para el Desarrollo (PNUD) Disponible en:http:// www.unv.org/fileadmin/docdb/pdf/2011/SWVR/Spanish/SWVR2011_\%5BSpa\%5D_ full_\%5B06\%5D_chapter3.pdf

Zubero, I (1994). Las nuevas condiciones de la solidaridad, Bilbao: Ediciones Desclée de Brouwer.

$\cos$ 